\title{
Dynamic optimal foraging theory explains vertical migrations of bigeye tuna
}

\author{
Thygesen, Uffe Høgsbro; Sommer, Lene; Evans, Karen; Patterson, Toby A.
}

Published in:
Ecology

Link to article, DOI:

10.1890/15-1130.1

Publication date:

2016

Document Version

Publisher's PDF, also known as Version of record

Link back to DTU Orbit

Citation $(A P A)$ :

Thygesen, U. H., Sommer, L., Evans, K., \& Patterson, T. A. (2016). Dynamic optimal foraging theory explains vertical migrations of bigeye tuna. Ecology, 97(7), 1852-1861. https://doi.org/10.1890/15-1130.1

\section{General rights}

Copyright and moral rights for the publications made accessible in the public portal are retained by the authors and/or other copyright owners and it is a condition of accessing publications that users recognise and abide by the legal requirements associated with these rights.

- Users may download and print one copy of any publication from the public portal for the purpose of private study or research.

- You may not further distribute the material or use it for any profit-making activity or commercial gain

- You may freely distribute the URL identifying the publication in the public portal

If you believe that this document breaches copyright please contact us providing details, and we will remove access to the work immediately and investigate your claim. 


\title{
Dynamic optimal foraging theory explains vertical migrations of Bigeye tuna
}

\author{
Uffe H. Thygesen,,${ }^{1,3}$ Lene Sommer, ${ }^{1}$ Karen Evans, ${ }^{2}$ and Toby A. Patterson ${ }^{2}$ \\ ${ }^{1}$ Center for Ocean Life, National Institute for Aquatic Resources, Technical University of Denmark, Lyngby, DK-2800, Denmark \\ ${ }^{2}$ CSIRO Oceans and Atmosphere National Research Flagship, Castray Esplanade, Battery Point, TAS 7004, Australia
}

\begin{abstract}
Bigeye tuna are known for remarkable daytime vertical migrations between deep water, where food is abundant but the water is cold, and the surface, where water is warm but food is relatively scarce. Here we investigate if these dive patterns can be explained by dynamic optimal foraging theory, where the tuna maximizes its energy harvest rate. We assume that foraging efficiency increases with body temperature, so that the vertical migrations are thermoregulatory. The tuna's state is characterized by its mean body temperature and depth, and we solve the optimization problem numerically using dynamic programming. With little calibration of model parameters, our results are consistent with observed data on vertical movement: we find that small tuna should display constant-depth strategies while large tuna should display vertical migrations. The analysis supports the hypothesis that the tuna behaves such as to maximize its energy gains. The model therefore provides insight into the processes underlying observed behavioral patterns and allows generating predictions of foraging behavior in unobserved environments.
\end{abstract}

Key words: bigeye tuna; dynamic programming; optimal foraging; vertical migrations.

\section{INTRODUCTION}

Knowledge of habitat usage of marine animals in terms of physiological constraints is of fundamental importance to understanding and predicting present and future distributions of these species. For tunas, physiological adaptation as a determinant of distribution has been the central focus of several studies, (e.g., Block 1991, Brill et al. 1994, Dickson and Graham 2004, Whitlock et al. 2015). Typically, these studies have required basic data on how tunas distribute themselves with respect to temperature and oxygen concentrations at depth (Brill et al. 2005). However,few studies (Kirby et al. 2000, Whitlock et al. 2015) have formally considered tradeoffs between physiological constraints and foraging returns.

Vertical migrations between the ocean surface and deeper water layers have been observed in many pelagic fish (Klimley et al. 2002, Dagorn et al. 2006, Thums et al. 2012, Nakamura et al. 2015). For Bigeye tuna (Thunnus obesus), these vertical migrations are particularly striking and well documented (Holland et al. 1992, Musyl et al. 2003). Migration of pelagic food sources associated with the deep (or sound) scattering layer has been recognised (e.g., Pearcy and Laurs 1966). Studies using active acoustic telemetry with simultaneous echosounder measurements of mesopleagic forage biomass have noted the associations of Bigeye tuna with the deep scattering layer (e.g., Josse et al. 1998). Over long periods,

Manuscript received 24 June 2015; revised 16 November 2015; accepted 6 January 2016; final version received 15 February 2016. Corresponding Editor: D. C. Speirs.

[3E-mail: uht@aqua.dtu.dk bigeye vertical movements conform to the pattern of night-time spent close to the surface and day-time residence between approximately 300-600 m (Musyl et al. 2003, Evans et al. 2008, Schaefer and Fuller 2010). Daytime behavior typically displays so-called "u-shaped" patterns (Musyl et al. 2003), where periods at depth are punctuated by rapid surfacing ascents, followed by equally fast descents back into deep water. Deep residency is associated with a tolerance to prolonged exposure to cold temperature water - Bigeye tuna regularly encounter ambient temperatures less than $10^{\circ} \mathrm{C}$ and as cold as $3^{\circ} \mathrm{C}$ (Swimmer et al. 2004, Evans et al. 2008). These adaptations for tolerance to cold, deep water has been suggested as a foraging strategy for avoiding overlap with other tunas with similar distribution such as yellowfin (Thunnus albacares) and skipjack (Katsuwonis pelamis), which are typically restricted to shallower and warmer waters (Lowe et al. 2000, Brill et al. 2005).

While u-shaped behavior has received considerable attention in the literature, Bigeye tuna do exhibit a variety of vertical movement behaviors which tend to be related to associations with bathymetric features or floating objects (Schaefer and Fuller 2005). Although improvements in tagging technology allow ever smaller individuals to be studied, there are few data covering the whole size range of bigeye and the behavior of bigeye smaller than a fork length of $0.6 \mathrm{~m}$ is not well known.

Temperature is not the only physical process affecting bigeye. For instance, oxygen concentrations may influence the tuna directly or their prey and thereby contribute to this surfacing behavior (Dagorn et al. 2000). Oxygen concentrations are likely to determine overall 
depths rather than surfacing behavior per se. This has been hypothesized by comparing fish in the Eastern Pacific Ocean, which generally forage at $300-400 \mathrm{~m}$ during the day; whereas in the Western Pacific Ocean, day time depths are typically $500-600 \mathrm{~m}$. In both regions, bigeye demonstrate vertical ascents (Evans et al. 2008). Therefore, u-shaped migrations are generally attributed to thermoregulation.

In common with other endothermic pelagic predators, it is thought that bigeye are attempting to maintain high muscle temperature and thus increased swimming speeds (Watanabe et al. 2015) by a combination of physiological and behavioral adaptations. Bigeye increase their rate of heat exchange rate during warming, while decreasing it during cooling. This is achieved by opening and closing of vascular counter-current heat exchangers. Heating excursions to the surface can therefore be made relatively short (Holland et al. 1992, Malte et al. 2007) while still resulting in average body temperature exceeding the average ambient temperature. The observed vertical behavior of Bigeye tuna can therefore be understood in terms of thermal thresholds dictating when the animal should stop feeding and travel to the surface to heat up, and conversely, when it is warm enough to descend on a foraging bout (Maury 2005). The underlying assumption behind such a threshold model, as well as behind the thermoregulation hypothesis in general, is that such a behavior is advantageous in terms of achieving increased overall foraging efficiency. However, the assumption of optimality of this thermoregulation strategy has not been tested.

In the absence of physiological constraints, optimal foraging theory suggests that bigeye should reside at depths where net energy intake is maximised, which during daytime is likely to be at the deep scattering layer (Josse et al. 1998, Bertrand et al. 2002). Being limited by their endothermic capacity, however, bigeye face a tradeoff between being present where prey is most abundant, and being warm enough to function and capture prey effectively. The profitability of warming excursions from the food-abundant deep scattering layer to the surface hinges on a significant increase in efficiency while foraging, and the major cost for the bigeye associated with such excursions, is likely to be that of lost opportunity; time spent warming is time not spent foraging. While previous studies (Holland et al. 1992, Lowe et al. 2000) have examined the physiological mechanics of the constraints, they have not attempted to examine if these tradeoffs can explain the striking changes in depth that bigeye exhibit. The framework of optimal foraging theory (Stephens and Krebs 1987, Houston and McNamara 1999, Clark and Mangel 2000) can identify behaviors which maximize overall foraging efficiency in situations where such tradeoffs are present. Although dynamic optimization models have been applied to explain tuna behavior near ocean fronts (Kirby et al. 2000), they have not been applied to the vertical migrations of Bigeye tuna feeding on deep scattering layers.
In this paper, our aim is to examine if the observed behavior of Bigeye tuna is quantitatively consistent with predictions from dynamic optimal foraging theory. We formulated a simple model of the energy gains of the fish, in which the instantaneous energy harvest rate depends not only on prey availability but also on body temperature. We make simplistic assumptions about the prey field, the temperature structure of the tuna and linkages between these and foraging success. We then pose an optimization model which identifies those behavioral strategies, i.e., those vertical movements, which result in the highest long-term energy harvest. We calibrate the model against a particular data set and compare the predicted behavioral patterns with those observed.

\section{Data, Model and Analysis \\ Bigeye vertical movement data}

Model predictions were qualitatively compared to data that were derived from archival tags implanted in the peritoneal cavity of juvenile bigeye in the northern Coral Sea in the western Pacific Ocean. See (Evans et al. 2008) for full details of tagging procedures and data collected. We focus on one particular individual, tagged with tag 99-216, which was released on October 13, 1999, at $16.03 \mathrm{~S}, 146.53 \mathrm{E}$, and for which $205 \mathrm{~d}$ of data were obtained. This individual had a length to caudal fork of $91 \mathrm{~cm}$ at the time of tagging. We base the model calibration on this particular individual and the particular time window displayed in Fig. 1, chosen arbitrary among those individuals and time periods where behavior was consistent for consecutive days.

\section{Model formulation}

Our model of a tuna and its energy harvest follows the state space approach to dynamic optimization (Houston and McNamara 1999, Clark and Mangel 2000). The key relationships in the model components are depicted in Fig. 2.

The tuna is represented with two state variables, viz. its depth $Z(t)$ and its body temperature, $T(t)$, for each time $t$. Both time domain and state space are continuous. We ignore internal temperature differences and treat the bigeye as a body of uniform temperature. The basic model consists of two coupled ordinary differential equations governing the dynamics of these state variables:

$$
\begin{aligned}
& \dot{Z}(t)=U(T(t)) \cdot \sin \Phi(t) \\
& \dot{T}(t)=h\left(T_{a}(Z(t))-T(t)\right)
\end{aligned}
$$

Here, $U(T)$ is swimming speed, which depends on the tuna's instantaneous body temperature $T$ (Fig. 2, bottom left). We do not consider the problem of optimal choice of swimming speed. The pitch angle $\Phi(t)$ is the angle at 

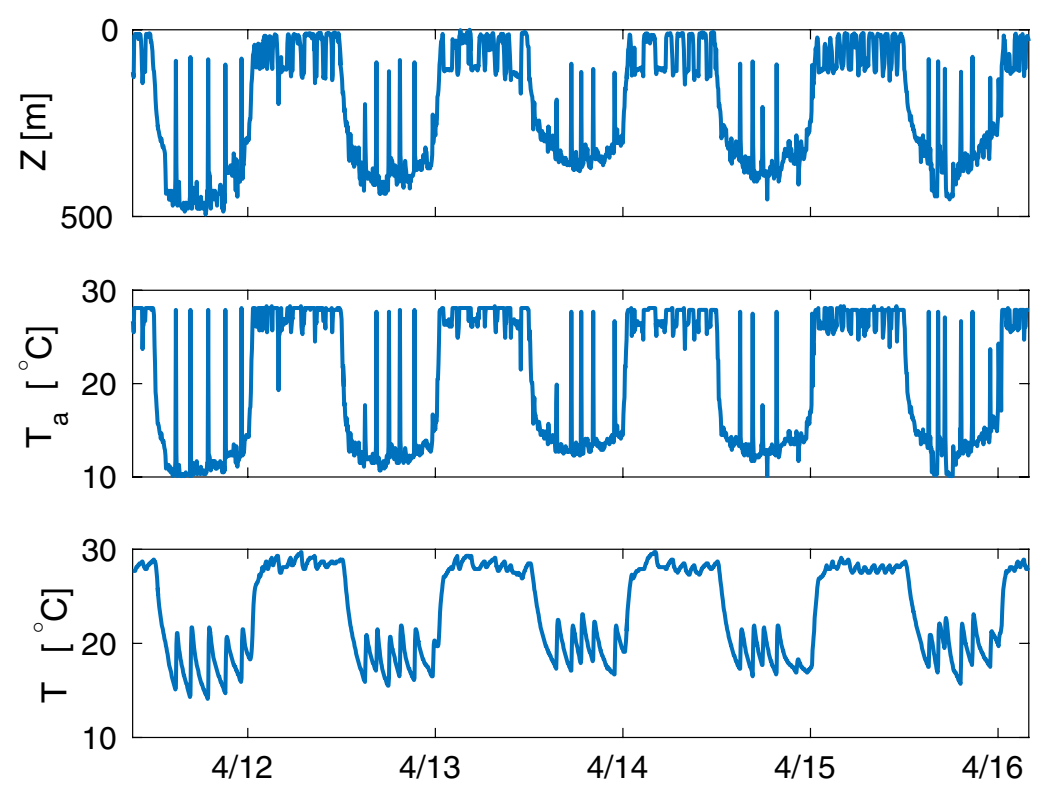

FIG. 1. Example of time series obtained from archival tag on Bigeye tuna. Top panel: Depth. Middle panel: Ambient water temperature. Bottom panel: Body temperature. Data from tag 99-216 (Evans et al. 2008) in April, 2002.

time $t$ between the tuna's velocity vector and horizontal, with $\Phi>0$ when the tuna descends. At each instant $t$, the tuna is free to choose its swimming direction $\Phi(t)$; our main contribution is to derive the optimal choice of $\Phi$ in each possible state of the bigeye and thus the optimal vertical migrations. The heating rate $h$ is assumed to depend only on the temperature difference $T_{a}-T$ between ambient water and body (Fig. 2, bottom right). The ambient temperature $T_{a}(z)$ depends on the depth (Fig. 2, top right).

We assume that the tuna behaves such as to maximize its average energy acquisition by feeding, the instantaneous rate $\dot{E}(t)$ of which is given by

$$
\dot{E}(t)=\rho(Z(t)) \cdot U(T(t)) \cdot \cos \Phi(t)
$$

Here, $\rho(z)$ measures energy harvested per distance traveled, and depends on instantaneous depth $z=Z(t)$ (Fig. 2, top left). This form equates energy harvest with a weighted swept volume and therefore ignores the specifics of prey encounter and capture. The inclusion of the term $\cos \Phi(t)$ implies that the tuna does not feed while it is migrating vertically, so effectively forces the bigeye to choose between migrating vertically and harvesting at its current location. The specific choice of a cosine function is arbitrary, but implies technical simplification since it matches the sine function in (1); see Appendix S1.

\section{Model components and parameterization}

In the following we go through the details of the model components. Specific parameter values are given in Table 1 and are found by calibrating the model against observed behavior as in Fig. 1.
Temperature profile.-The (ambient) temperature profile of the water column follows the model given by Maury (2005), where the temperature $T_{a}(z)$ at depth $z$ is written

$$
T_{a}(z)=T_{0}-\left(p \cdot z+\Delta T_{\text {clin }}\right) \cdot \frac{z^{\lambda}}{z_{\text {clin }}^{\lambda}+z^{\lambda}}
$$

See Fig. 2, top right. Here, $T_{0}$ is the surface temperature, $z_{\text {clin }}$ controls the depth of the thermocline, $\Delta T_{\text {clin }}$ governs the temperature drop over the thermocline, and $p$ is the asymptotic temperature gradient $-\partial T_{a} / \partial z$ far below the thermocline. The dimensionless parameter $\lambda$ controls the sharpness of the thermocline, i.e. large $\lambda$ implies a sharp transition. These parameters are tuned by hand to match the calibration data included in Fig. 2, top right, obtained from tag 99-216 (Evans et al. 2008) on a selected day, April 11, 2002.

Food distribution.-Several studies (e.g., Josse et al. 1998, Bertrand et al. 2002) have provided empirical evidence for bigeye associating with the deep scattering layer (DSL) during daytime. For simplicity and generality, we postulate a simple bell-shaped vertical distribution of food availability $\rho(z)$ :

$$
\rho(z)=\rho_{0}+\left(\rho_{m}-\rho_{0}\right) \exp \left(-\frac{1}{2} \frac{\left(z-z_{S}\right)^{2}}{\sigma^{2}}\right)
$$

See Fig. 2, top left. We assume a constant environment, i.e. $\rho$ does not depend on time; this profile reflects daytime conditions. We define food availability as energy harvested per distance traveled, which combines prey density, energy contents of prey, detection distance, 

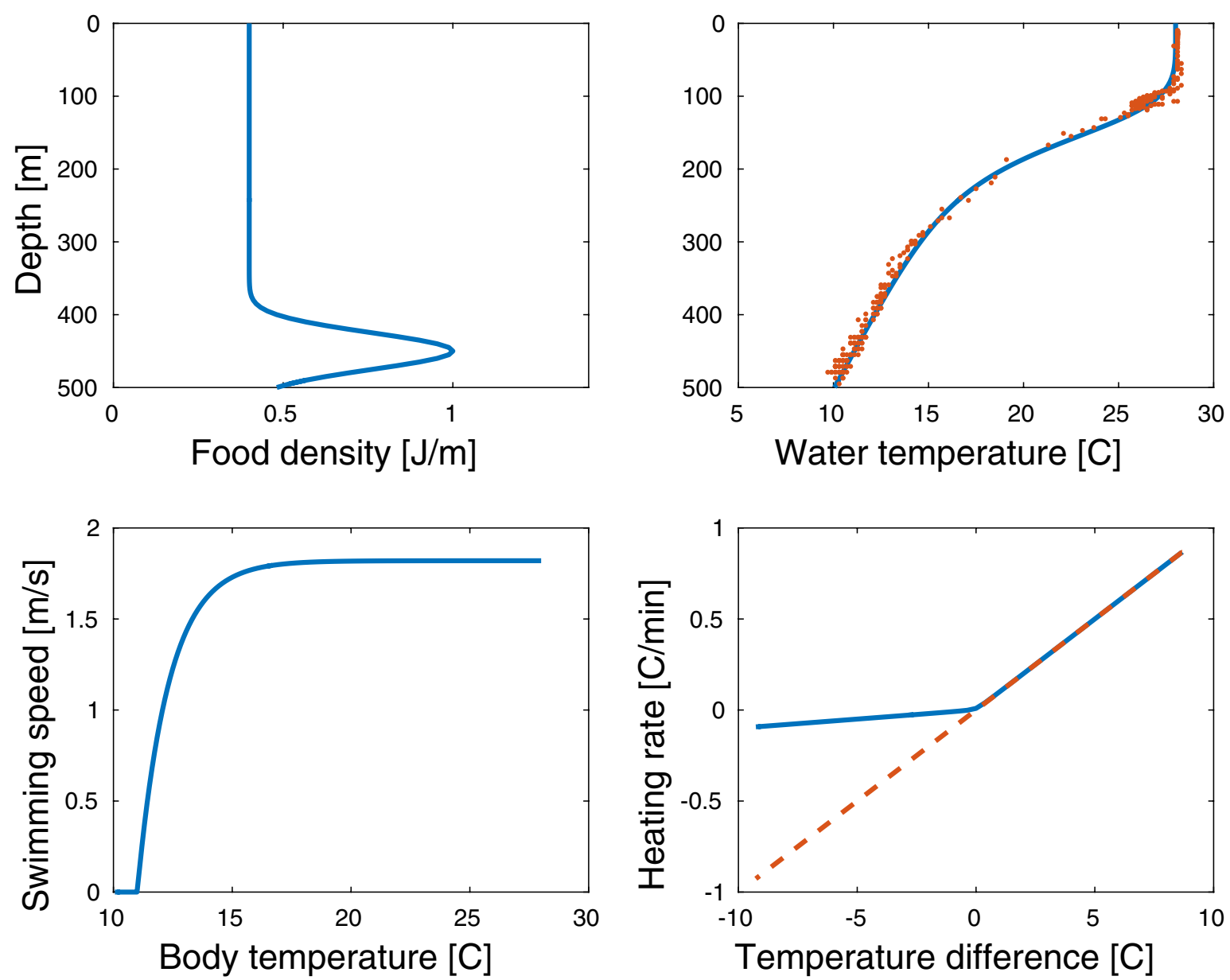

FIG. 2. Key functional dependencies in model. Top left: Hypothesized distribution of available food in the water column, mimicking daytime conditions. Top right: Temperature profile of the water column. Included are data points obtained from tag 99-216 on April 11, 2002. Bottom left: Hypothesized swimming speed as function of body temperature. Bottom right: Hypothesized heating rate as function of temperature difference. Solid: A bigeye of fork length $0.91 \mathrm{~m}$. Dashed: A bigeye of fork length $0.5 \mathrm{~m}$ for which the cooling rate is identical to the heating rate.

and capture success. We focus on relative energy harvest between different migration patterns and do not attempt to assign an absolute value to energy harvest, so we assume that the maximum availability equals $\rho_{m}=1 \mathrm{~m}^{-1}$. We set the depth of maximum food availability to $z_{S}=450 \mathrm{~m}$ to match the prevalent position of the fish during dives; see Fig. 1. The width of the DSL is set to $2 \sigma=50 \mathrm{~m}$ which matches the spread in dive depths as derived from tag data. Both the depth $z_{S}$ and the width $2 \sigma$ compare to typical features of DSL's. $\rho_{0}$ is the relative food availability far from the DSL, assumed constant and equal to $\rho_{0}=0.4 \rho_{m}$ to ensure that staying at the surface is in fact an alternative to targeting the DSL.

Thermodynamics. - The thermodynamic model is a simplification of (Brill et al. 1994), in that our model ignores temperature differences inside the body of the tuna and represents its thermal state with one body temperature $T(t)$. The function $h$, appearing in (2) and determining the heating rate of the tuna, is depicted in Fig. 2, bottom right, and has the particular form:

$$
h(\Delta T)=\frac{1}{2}\left(\left(k_{h}+k_{l}\right) \cdot \Delta T+\left(k_{h}-k_{l}\right) \sqrt{(\Delta T)^{2}+\tau^{2}}\right)
$$

where $\Delta T=T_{a}-T$ is the difference from body temperature to ambient water temperature. This form ignores internal heat production, as $h(0)=0$, and is a hyperbolic transition between two linear responses, characterized by a high heat exchange rate $k_{h}$ when heating and a low heat exchange rate $k_{l}$ when cooling. The tuna obtains this transition by mediating the efficiency of its vascular counter-current heat exchangers. The width of the transition zone is given by $\tau=0.2^{\circ} \mathrm{C}$ and is so small that the relationship appears almost piecewise linear.

The specific values of $k_{h}, k_{l}$ and $\tau$ are given in Table 1 . These parameters are set by calibrating cooling and heating profiles against data from tag 99-216 as in Fig. 1. 
TABLE 1. Model parameters, calibrated against tag 99-216 (Evans et al. 2008).

\begin{tabular}{|c|c|c|c|}
\hline Symbol & Parameter & $\begin{array}{l}\text { Default } \\
\text { value }\end{array}$ & Unit \\
\hline$T_{0}$ & Surface temperature & 28 & ${ }^{\circ} \mathrm{C}$ \\
\hline$z_{\text {clin }}$ & Depth of thermocline & 160 & $\mathrm{~m}$ \\
\hline$\Delta T_{\text {clin }}$ & $\begin{array}{l}\text { Temperature drop over } \\
\text { thermocline }\end{array}$ & 8 & ${ }^{\circ} \mathrm{C}$ \\
\hline$p$ & $\begin{array}{l}\text { Temperature gradient below } \\
\text { thermocline }\end{array}$ & 0.02 & ${ }^{\circ} \mathrm{C} / \mathrm{m}$ \\
\hline$\lambda$ & Sharpness of thermocline & 5 & -- \\
\hline$z_{S}$ & Depth of peak food density & 450 & $\mathrm{~m}$ \\
\hline$\sigma$ & Thickness of food layer & 25 & $\mathrm{~m}$ \\
\hline$\rho_{m}$ & $\begin{array}{l}\text { Peak food abundance in the deep } \\
\text { scattering layer }\end{array}$ & 1 & $\mathrm{~m}^{-1}$ \\
\hline$\rho_{0}$ & $\begin{array}{l}\text { Food abundance far from the } \\
\text { deep scattering layer }\end{array}$ & 0.4 & $\mathrm{~m}^{-1}$ \\
\hline$L$ & Fork length & 0.91 & $\mathrm{~m}$ \\
\hline$k_{l}$ & Heat exchange rate while cooling & 0.01 & $\min ^{-1}$ \\
\hline$k_{h}$ & Heat exchange rate while heating & 0.1 & $\min ^{-1}$ \\
\hline$\tau$ & $\begin{array}{l}\text { Range of transition between } k_{l} \\
\text { and } k_{h}\end{array}$ & 0.2 & ${ }^{\circ} \mathrm{C}$ \\
\hline$U_{m}$ & $\begin{array}{l}\text { Maximum swimming speed in } \\
\text { fork lengths }\end{array}$ & 2 & $\mathrm{~s}^{-1}$ \\
\hline$T_{d}$ & $\begin{array}{l}\text { Temperature below which the fish } \\
\text { stalls }\end{array}$ & 11 & ${ }^{\circ} \mathrm{C}$ \\
\hline$\lambda$ & $\begin{array}{l}\text { Sensitivity of speed to } \\
\text { temperature }\end{array}$ & 0.75 & ${ }^{\circ} \mathrm{C}^{-1}$ \\
\hline
\end{tabular}

The time constant of cooling, $1 / k_{l}=100 \mathrm{~min}$, is longer than the cooling times reported by Malte et al. (2007); the difference could possibly be explained by our model not including internal heat production which would slow down cooling. The time scale of heating, $1 / k_{h}=10 \mathrm{~min}$, results in a ratio $k_{h} / k_{l}=10$ which is consistent with the findings of Malte et al. (2007).

For a smaller individual of fork length $0.5 \mathrm{~m}$, we assume that the heating rate is unchanged (Malte et al. 2007), but hypothesize that the counter-current heat exchange system has not yet developed. Therefore it has a cooling time which is identical to the heating time, i.e., an entirely linear response (Fig. 2, bottom right).

Note that the exchange rates $k$ depend only on instantaneous temperatures, i.e. the fish is able to alter its $k$ instantaneously in response to temperature changes. Although this is not strictly realistic, Holland et al. (1992) suggested that the response time of the fish was approximately $45 \mathrm{~s}$. As the sampling interval between data points used to inform the models was $4 \mathrm{~min}$, there should be no need to include the response time of the fish.

Swimming speed.-We assume that swimming speed depends only on fork length $L$ and body temperature $T$. The exact functional form of this dependence is not well known, so we assume a simple form

$$
U=U_{m} \cdot L \cdot\left(1-\exp \left(-\lambda\left(T-T_{d}\right)\right) \quad \text { when } \quad T \geq T_{d}\right.
$$

Here $T_{d}=11^{\circ} \mathrm{C}$ is the minimum body temperature required by the bigeye to maintain swimming. When $T \leq T_{d}$, we assume that the fish is stationary, $U=0$. Since this implies that the fish cannot move back to warmer waters layers, $T_{d}$ serves as a lower limit of the range of body temperatures and the optimal behavior will avoid reaching this limit. (See Fig. 2, bottom left.) At high temperatures, the swimming speed is unconstrained by body temperature and equals $U_{m}=2$ fork lengths per second. The parameter $\lambda=0.75^{\circ} \mathrm{C}^{-1}$ controls the width of the temperature range where swimming speed is limited by body temperature.

\section{The optimization problem}

We assume that the tuna chooses its trajectory, i.e., the pitch angle $\Phi(t)$ as a function of time $t$, in order to maximize the total harvested energy $E\left(t_{1}\right)-E\left(t_{0}\right)$ over a long time interval $\left[t_{0}, t_{1}\right]$. The terminal time $t_{1}$ can for example be thought of as the time of sunset when bigeye have been observed to switch from deeper daytime depths to shallower nighttime depths (e.g., Evans et al. 2008). This optimal energy harvest will depend on the initial time $t=t_{0}$ and the initial state $z=Z(0), T=T(0)$, and can hence be written $V(z, T, t)$. It follows from the theory of dynamic optimization (Bertsekas 2005) that this so-called value function $V$ satisfies the HamiltonJacobi-Bellman equation

$$
\frac{\partial V}{\partial t}+\sup _{\phi}\left[\frac{\partial V}{\partial z} \dot{Z}+\frac{\partial V}{\partial T} \dot{T}+\dot{E}\right]=0
$$

In common with ecological literature on dynamic programming (Houston and McNamara 1999, Clark and Mangel 2000), we denote this value function as the "fitness function." This should not be taken too literally, but the underlying argument is that energy harvested may ultimately be invested in reproduction, and the nomenclature also highlights that the animal behaves such as to maximize fitness, which in this particular situation amounts to forage as efficiently as possible. We focus on the long-term situation, where the fitness function can be written

$$
V\left(Z, T, t_{0}\right)=V_{0}(Z, T)+\gamma \cdot\left(t_{1}-t_{0}\right)
$$

Here, $\gamma$ is the long-term average rate of energy acquisition, while $V_{0}(Z, T)$ is a correction to the average energy harvest $\gamma \cdot\left(t_{1}-t_{0}\right)$ depending on the current state. We solve the Hamilton-Jacobi-Bellman equation numerically to find $V_{0}$ and $\gamma$. From the solution, we can construct the optimal pitch angle $\Phi$ as a function of depth $Z$ and temperature $T$, which allows us to solve the differential Eqs (1) and (2), numerically and thus obtain trajectories of depth and body temperature. See Appendix S1 for further details on the analytical and numerical steps involved in this. 


\section{RESULTS}

\section{Periodic optimal trajectories}

We now consider the particular set of parameters in Table 1, which was obtained by calibrating the model against data from tag 99-216. The resulting optimal trajectories are periodic, where a cycle consists of heating at the surface, diving to the DSL, feeding while cooling, and then resurfacing to heat again in a new cycle (Fig. 3, right).

For these parameters, a long-term average rate of energy harvest of $\gamma=1.64 \mathrm{~s}^{-1}$ is calculated. To interpret this result, a theoretical upper bound of $U_{m} \cdot L \cdot \rho_{m}=1.82 \mathrm{~s}^{-1}$ would be obtained if the tuna was able to feed continuously at the deep scattering layer at its maximum swimming speed, i.e. unconstrained by temperature. The predicted overall feeding rate achieved by the optimal behavioral strategy is therefore $90 \%$ of the theoretical upper bound.

The fitness function $V_{0}(z, T)$ is shown in Fig. 3 (left). Recall that it is optimal for the tuna to move vertically towards regions with higher fitness. When the tuna is warm, the optimal behavioral choice is therefore to dive to the depth where food is most available and thus start foraging. Conversely, for a cold tuna, the fitness is higher at the surface than at depth, and the optimal choice is to ascend to the surface. It is this difference that causes the optimal trajectories to be oscillatory, as seen in Fig. 3 (right). This "quiver" plot displays the flow field in state space that an optimal tuna follows. Included is one optimal trajectory, where the tuna initially is at the surface in thermal equilibrium, then dives and initiates foraging. Note that the state of the bigeye then very quickly approaches a limit cycle.

The predicted optimal trajectories are seen as time series in Fig. 4, left. Included is also actual time series obtained from tag 99-216 on April 11, 2002. Qualitatively, there is a high degree of agreement between model predictions and observations in terms of temperature thresholds, and consequently also in terms of depth range and duration of the cycle.

Some detailed features in the data are not reproduced by the model. Most notably, at the start of this window of the time series, the sun rises and light penetrates gradually down the water column, while the deep scattering layer migrates down, causing the tuna to also descend gradually. A similar phenomenon can perhaps explain the slightly shallower dive at the end of the window, at dusk. These features are not included in the model, which assumes a stationary environment. In addition, the model does not predict the exact timing of the surfacing events, but rather a thermal range: When the tuna cools to the lower limit of this ranges, this initiates the surfacing. We see that this thermal range is predicted quite accurately.

\section{Size-induced changes in behavior}

Examining the effect of the fork length on predicted dynamics, we assumed that smaller bigeye are unable to control their heat exchange rates and therefore has a linear thermodynamic response (Fig. 2, bottom right). Further, smaller bigeye swim slower since swimming speed scales with body length. Thus foraging at depth is less profitable for smaller bigeye, and at some critical length vertical migrations are inferior to staying at the surface. Fig. 4, left panels, include optimal trajectories for a bigeye of fork length $0.5 \mathrm{~m}$ (dashed lines). The surface strategy adopted by this fish yields a feeding rate which is $40 \%$ of the theoretical upper bound. The transition between u-shaped behavior and surface dwelling was predicted to occur near a fork length of $0.55 \mathrm{~m}$.
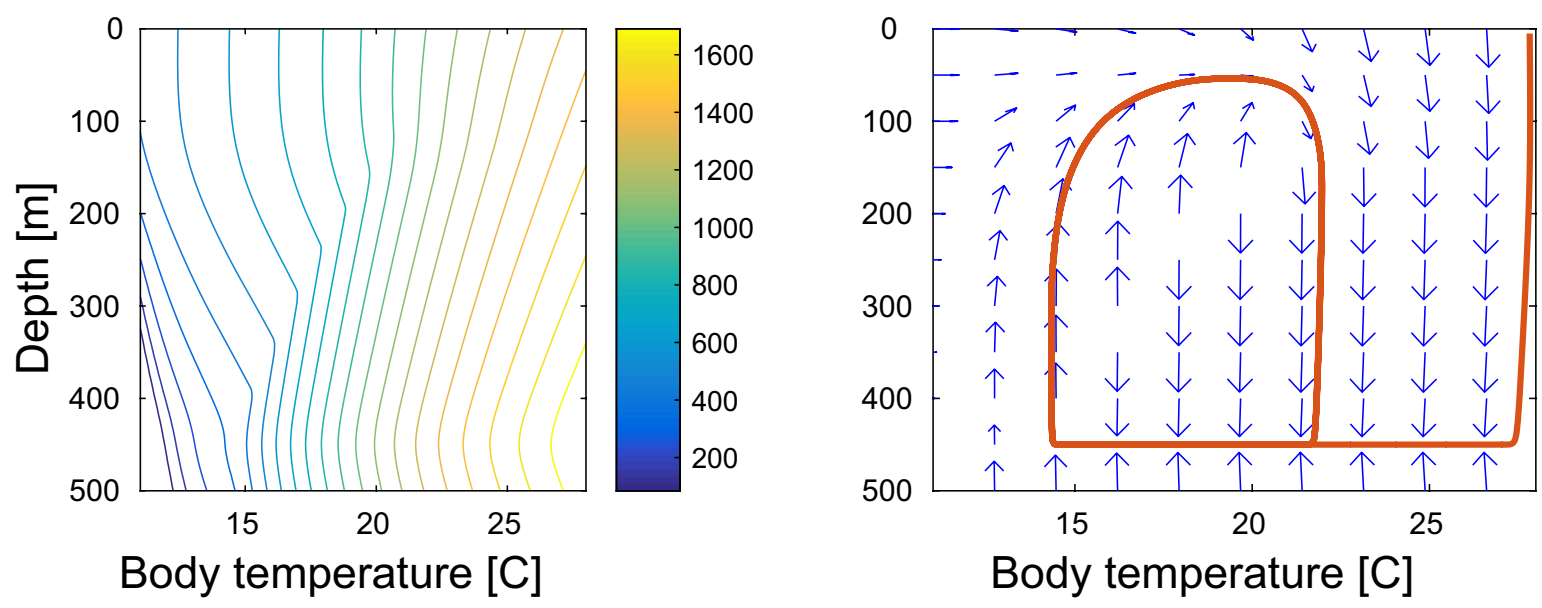

FIG. 3. Left panel: Fitness landscape on state space: Contour plot of the fitness function $V_{0}(z, T)$ for reference parameters. Right panel: Phase portrait of the optimal dynamics. Included is one optimal trajectory starting in thermal equilibrium at the surface. 

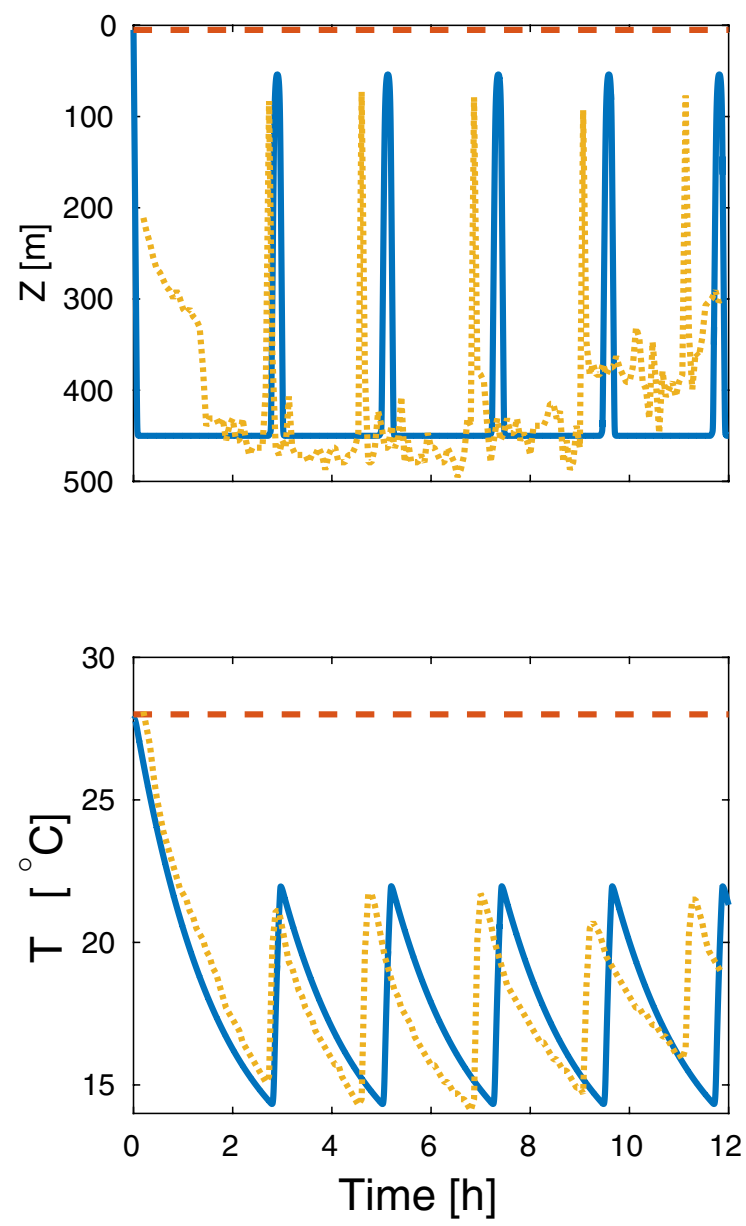

FIG. 4. Time series of depth (upper panel) and body temperature (lower panel). Predictions from the optimization model for an individual of fork length $0.91 \mathrm{~m}$ (solid) and $0.5 \mathrm{~m}$ (dashed). Included is also observed time series (dotted) from the individual tagged with tag 99-216 on April 11, 2002 (Evans et al. 2008).

Since the model is calibrated only against larger bigeyes, this value is unlikely to be very accurately determined.

\section{DISCUSSION}

With little calibration, our optimization model yields predictions that are consistent with observed patterns of daytime behavior in bigeye. Large individuals are predicted to feed in the deep scattering layer but feeding is punctuated with warming ascents. Periods, thermal ranges, and depth ranges of the resulting pattern are consistent with observations.

For smaller tuna $(<0.55 \mathrm{~m})$ the model predicts a vertical distribution constrained to warmer surface waters. This difference in predicted behavior between small and large bigeye is due to different swimming speeds, cooling rates, and our assumption that small bigeye cannot thermoregulate as efficiently. The diving behavior of small bigeye is poorly known and the smallest individual in the data base for this study had a fork length of $77 \mathrm{~cm}$ (Evans et al. 2008). While it is thought that small bigeye are more associated with surface depths, and indeed are caught by purse seine fisheries when in mixed surface schools with skipjack and yellowfin, it is not know at which size the transition from near continuous surface orientated behavior to the u-shaped diving occurs. A further complication is that this transition will also be affected by the temperature profile and the vertical distribution of prey at the given location. Recent developments in tags allow smaller individuals to be tagged, and it must be anticipated that further data on smaller Bigeye tuna will be available, allowing this question to be elucidated.

Most importantly, the predicted behavioral choices largely agree with observed behavior; this emergent behavior does not follow directly from model calibration but testifies that the model captures essential tradeoffs faced by the bigeye, despite model simplicity. We discuss the most important simplifying assumptions below.

\section{Time horizons and stationarity}

Here, we have assumed a stationary environment; in effect an infinitely long day. It is interesting to consider the effects of including a repeating sequence of night, dawn, day, and dusk. Such a model would include diel changes in light levels and thus visual ranges, which trigger a diel migration of the deep scattering layer, where zooplankton and forage fish (e.g., myctophids) migrate to surface waters at night and to deeper waters at night, driven by predator avoidance. (See Mangel and Clark 1988 for an example involving zooplankton, and Sainmont et al. 2013 for a framing as a game between predators and prey.) At night, food abundance would be highest in the optimal thermal habitat, and the tradeoffs which constrain the vertical movements during the daytime would disappear, resulting in an obvious surface behavior during the night without behavioral thermoregulation. Meanwhile, the daytime results would be mostly unchanged from the present study, although one would expect slight deviations from the stationary strategies at dawn and dusk. For example the bigeye could potentially prolong the last dive undertaken during the day, knowing that night is approaching and therefore it would not obtain full advantage from a heating excursion.

\section{$U$-shaped behavior is not ubiquitous}

In reality, bigeye do not always undertake the u-shaped vertical movements considered in this model but demonstrate variable vertical behavior (e.g., Schaefer and Fuller 2002, Musyl et al. 2003, Evans et al. 2008). Bigeye are known to associate with seamounts or floating objects (Robert et al. 2014) for extended periods, and during these associations they tend to remain more surface orientated, even if the precise reasons for this behavior is unknown and debated (Fréon and Dagorn 2000). 
Additionally, it is possible that particular feeding bouts could be so successful that the tuna cannot feed any further. This could negate its need to continue feeding in what is an otherwise physiologically stressful environment at depth, and instead cause the tuna to stay in warm surface waters to accelerate digestion. Studies which correlate fine scale movement behavior and feeding activity are unavailable for bigeye, but do exist for other species including juvenile bluefin tuna where a post-prandial digestion signal can be discerned from archival tags (Bestley et al. 2010, Clark et al. 2010, Whitlock et al. 2013). The development of endothermic capacity in the vascular physiology of bigeye is considered intermediate between yellowfin tunas and the bluefin species, and they do not appear to display a visceral warming signal like bluefin (see Malte et al. 2007, for a comprehensive discussion of the differences between bigeye and other tuna species).

\section{Swimming energetics and heat losses}

The energetic model here is simplistic in that it includes only feeding uptake and excludes both heat loss and swimming energetics. Constructing a full energy budget would be challenging because it would require absolute estimates of contributions to the energy budget, not just relative ones. i.e., how many joules are gained from feeding, how much is lost due to swimming, how much is lost due to cooling? However, obtaining such data would be difficult and would require strong assumptions about the proportion of particular prey in each feed and its energetic value. Moreover, even if sufficient data were available, we might only be able to reach the obvious conclusion that migrations would only be optimal if sufficient food is present at depth. We note that heat losses and swimming energetics may be important terms in the energy budget of the tuna, and therefore important to include when scaling up the results to energetics of the population, even if this study has demonstrated that the model can be calibrated to match data without these terms.

\section{Un modelled physiological constraints: oxygen concentration}

Ambient oxygen concentrations are known to impact cardiac performance in tunas, even if empirical data on oxygen tolerances of bigeye, and physiological response to hypoxia, are few (Bushnell et al. 1990, Brill 1994). While oxygen concentration generally decreases with depth, bigeye have been found to spend time in water with oxygen levels down to $1 \mathrm{~mL} \mathrm{O}_{2} / \mathrm{L}$ (Musyl et al. 2003, Evans et al. 2008), and bigeye are not likely to experience limiting oxygen concentrations in their diving range (Gunn et al. 1999, Musyl et al. 2003) outside the eastern Pacific Ocean, where the oxygen minimum zone is shallower than in other parts of the Pacific Ocean. Therefore we did not include oxygen requirements and availability in our model even if including this element could expand the range of applicability of our model. Although both temperature and oxygen divide the water column into a more suitable surface habitat and a less suitable deep habitat, the dynamic responses and the associated costs differ, and further studies are required to investigate the extra ecological insight that could be gained by such a model.

\section{Deep scattering layer characteristics}

The depth of the deep scattering layer varies depending on local conditions (Powell and Ohman 2015) and season (Wang et al. 2014). The distribution of food resources over the water column, and in particular the food availability in the deep scattering layer relative to the surface, will vary in reality and was simply postulated here. During initial experiments with the model, varying the parameters describing the food distribution, we found that the optimal bigeye consistently targets the depth of maximum food availability during dives, whenever the optimal behavior is u-shaped, and that the width of the DSL has little impact. In principle, characteristics of the back-scattering signals may provide empirical support for this, and overlap between bigeye and DSL has been observed (Josse et al. 1998). However, quantitative data associated with the expansive habitats which bigeye occupy are lacking.

\section{Fixed depth/temperature relationship}

Similarly, the depth/temperature relationship considered here, while derived from data collected by from a tagged bigeye, does not consider the range of conditions that bigeye encounter. It is possible that changes to the surface temperature or mixed-layer depth could induce changes in vertical behavior. A sensitivity study of the model could ascertain how much difference this makes.

\section{Variability between individuals}

Besides environmental variability, also individual characteristics influence the tunas ability to forage at depth. Here, we only investigated the effect of swimming speed as controlled by individual size, but variability in all parameters must be expected even between individuals of the same size. It is not clear to what degree variability in vertical movements is derived from difference between individuals, and how much is derived from differences between habitats characteristics. Further studies involving sensitivity analysis as well as calibration against different data sets could illuminate this.

\section{Comparisons with observations}

Our comparisons to observations in this study have been limited to a small snapshot of bigeye diving behavior. While this is a restricted and informal test of the model, our aims were simply to examine the general dynamics of the model system, given our assumptions about physiology, habitat, and objectives of bigeye. Our modeling was successful in 
replicating empirical observations of daytime vertical movement behavior of bigeye. Further work is required to examine how the model performs when different individuals are exposed to similar ocean regimes, or the same individual is exposed to different ocean regimes. To this end, it would be better to estimate model parameters from data, rather than assume them or calibrate them by hand. Such models could be specified in a hierarchical fashion (e.g., see Gelman et al. 2014, for a general text), with distributions on model parameters accounting for variation between individuals. However, it remains unclear how to best estimate parameters in dynamic optimal foraging models, utilizing data sets obtained with modern animal tagging technology. Doing so is a large research enterprise well beyond the scope of the current paper, but a highly interesting direction for future developments.

\section{CONCLusion}

This paper has presented a dynamic optimal foraging model of Bigeye tuna that successfully reproduces observed behavior. Dynamic programming was used to derive optimal vertical strategies given models of temperature at depth, the location of the deep scattering layer, and size-dependent swimming efficiency and thermodynamics. This has allowed a qualitative evaluation of the tradeoffs made by foraging bigeye and how these are influenced by size. The model predicts that smaller fish adopt surface-oriented strategies while larger fish initiate behavioral endothermy through spike warming ascents. We have discussed how our model could be extended and further compared with data. Two recent reviews have highlighted the need for further understanding of tuna behavior for management (Evans et al. 2015, Young et al. 2015). Developments built upon the approach considered here should facilitate the construction of more biologically realistic process models of tuna behavior and movement, and ultimately may aid in prediction of tuna behavior in changing ocean environments.

\section{ACKNOWLEDGMENTS}

The Centre for Ocean Life is supported by the Villum Foundation.

\section{Literature Cited}

Bertrand, A., F.-X. Bard, and E. Josse. 2002. Tuna food habits related to the micronekton distribution in french polynesia. Marine Biology 140:1023-1037.

Bertsekas, D. P. 2005. Dynamic programming and optimal control, volume 1. Athena Scientific, Belmont, Massachusetts, USA.

Bestley, S., T. A. Patterson, M. A. Hindell, and J. S. Gunn. 2010. Predicting feeding success in a migratory predator: integrating telemetry, environment, and modeling techniques. Ecology 91:2373-2384.

Block, B. 1991. Endothermy in fish: thermogenesis, ecology and evolution. Biochemistry and Molecular Biology of Fishes 1:269-311.

Brill, R. W. 1994. A review of temperature and oxygen tolerance studies of tunas pertinent to fisheries oceanography, movement models and stock assessments. Fisheries Oceanography 3:204-216.

Brill, R. W., H. Dewar, and J. B. Graham. 1994. Basic concepts relevant to heat transfer in fishes, and their use in measuring the physiological thermoregulatory abilities of tunas. Environmental Biology of Fishes 40:109-124.

Brill, R. W., K. A. Bigelow, M. K. Musyl, K. A. Fritsches, and E. J. Warrant. 2005. Bigeye tuna (Thunnus obesus) behavior and physiology and their relevance to stock assessments and fishery biology. Collective Volume of Scientific Papers ICCAT 57:142-161.

Bushnell, P. G., R. W. Brill, and R. E. Bourke. 1990. Cardiorespiratory responses of skipjack tuna (Katsuwonus pelamis), yellowfin tuna (Thunnus albacares), and Bigeye tuna (Thunnus obesus) to acute reductions of ambient oxygen. Canadian Journal of Zoology 68:1857-1865.

Clark, C. and M. Mangel. 2000. Dynamic state variable models in ecology: methods and applications. Oxford University Press, New York, New York, USA.

Clark, T., W. Brandt, J. Nogueira, L. Rodriguez, M. Price, C. Farwell, and B. Block. 2010. Postprandial metabolism of pacific bluefin tuna (Thunnus orientalis). The Journal of experimental biology 213:2379-2385.

Dagorn, L., P. Bach, and E. Josse. 2000. Movement patterns of large Bigeye tuna (Thunnus obesus) in the open ocean, determined using ultrasonic telemetry. Marine Biology 136: 361-371.

Dagorn, L., K. Holland, J.-P. Hallier, M. Taquet, G. Mareno, G. Sancho, D. Itano, R. Aumeeruddy, C. Girard, J. Million, and A. Fontaineau. 2006. Deep diving behavior observed in yellowfin tuna (Thunnus albacares). Aquatic Living Resources 19:85-88.

Dickson, K. A. and J. B. Graham. 2004. Evolution and consequences of endothermy in fishes. Physiological and Biochemical Zoology 77:998-1018.

Evans, K., A. Langley, N. P. Clear, P. Williams, T. Patterson, J. Sibert, J. Hampton, and J. S. Gunn. 2008. Behaviour and habitat preferences of Bigeye tuna (Thunnus obesus) and their influence on longline fishery catches in the western Coral Sea. Canadian Journal of Fisheries and Aquatic Sciences 65:2427-2443.

Evans, K., J. Young, S. Nicol, D. Kolody, V. Allain, J. Bell, J. Brown, A. Ganachaud, A. Hobday, B. Hunt, J. Innes, A. S. Gupta, E. van Sebille, R. Kloser, T. Patterson, and A. Singh. 2015. Optimising fisheries management in relation to tuna catches in the western central pacific ocean: a review of research priorities and opportunities. Marine Policy 59:94-104.

Fréon, P. and L. Dagorn. 2000. Review of fish associative behaviour: toward a generalisation of the meeting point hypothesis. Reviews in Fish Biology and Fisheries 10:183-207.

Gelman, A., J. B. Carlin, H. S. Stern, and D. B. Rubin. 2014. Bayesian data analysis, volume 2. Taylor \& Francis, Abingdon, UK.

Gunn, J., J. Hampton, K. Evans, N. Clear, T. Patterson, K. Bigelow, A. Langley, B. Leroy, P. Williams, N. Miyabe, et al. 1999. Migration and habitat preferences of Bigeye tuna, Thunnus obesus, on the east coast of australia. Technical Report 109, CSIRO Marine Research. Final report to the Fisheries Research and Development Corporation.

Holland, K. N., R. W. Brill, R. K. Chang, J. R. Sibert, and D. A. Fournier. 1992. Physiological and behavioural thermoregulation in Bigeye tuna (Thunnus obesus). Nature 358:410-412.

Houston, A. and J. McNamara. 1999. Model of adaptive behaviour. An approach based on state. Cambridge University Press, Cambridge, UK.

Josse, E., P. Bach, and L. Dagorn. 1998. Simultaneous observations of tuna movements and their prey by sonic tracking and acoustic surveys. Hydrobiologia 371:61-69. 
Kirby, D., Ø. Fiksen, and P. Hart. 2000. A dynamic optimisation model for the behaviour of tunas at ocean fronts. Fisheries Oceanography 9:328-342.

Klimley, A. P., S. C. Beavers, T. H. Curtis, and S. J. Jorgensen. 2002. Movements and swimming behavior of three species of sharks in La Jolla Canyon, California. Environmental Biology of Fishes 63:117-135.

Lowe, T., R. Brill, and K. Cousins. 2000. Blood oxygen-binding characteristics of Bigeye tuna (Thunnus obesus), a highenergy-demand teleost that is tolerant of low ambient oxygen. Marine Biology 136:1087-1098.

Malte, H., C. Larsen, M. Musyl, and R. Brill. 2007. Differential heating and cooling rates in Bigeye tuna (Thunnus obesus Lowe): a model of non-steady state heat exchange. Journal of Experimental Biology 210:2618.

Mangel, M. and C. W. Clark. 1988. Dynamic modeling in behavioral ecology. Princeton University Press, Princeton, New Jersey, USA.

Maury, O. 2005. How to model the size-dependent vertical behaviour of bigeye (Thunnus obesus) tuna in its environment. Collective Volume of Scientific Papers ICCAT 57:115-126.

Musyl, M. K., R. W. Brill, C. H. Boggs, D. S. Curran, T. K. Kazama, and M. P. Seki. 2003. Vertical movements of Bigeye tuna (Thunnus obesus) associated with islands, buoys, and seamounts near the main hawaiian islands from archival tagging data. Fisheries Oceanography 12:152-169.

Nakamura, I., Y. Goto, and K. Sato. 2015. Ocean sunfish rewarm at the surface after deep excursions to forage for siphonophores. Journal of Animal Ecology 84:590-603.

Pearcy, W. G. and R. Laurs. 1966. Vertical migration and distribution of mesopelagic fishes off oregon. Deep Sea Research and Oceanographic Abstracts 13:153-165.

Powell, J. R. and M. D. Ohman. 2015. Changes in zooplankton habitat, behavior, and acoustic scattering characteristics across glider-resolved fronts in the southern california current system. Progress in Oceanography 134:77-92.

Robert, M., L. Dagorn, and J. L. Deneubourg. 2014. The aggregation of tuna around floating objects: what could be the underlying social mechanisms? Journal of Theoretical Biology 359:161-170.

Sainmont, J., U. H. Thygesen, and A. W. Visser. 2013. Diel vertical migration arising in a habitat selection game. Theoretical Ecology 6:241-251.

Schaefer, K. M. and D. W. Fuller. 2002. Movements, behavior, and habitat selection of Bigeye tuna (Thunnus obesus) in the eastern equatorial pacific, ascertained through archival tags. Fishery Bulletin 100:765-788.

Schaefer, K. and D. Fuller. 2005. Behavior of bigeye (Thunnus obesus) and skipjack (Katsuwonus pelamis) tunas within aggregations associated with floating objects in the equatorial eastern pacific. Marine Biology 146:781-792.

Schaefer, K. M. and D. W. Fuller. 2010. Vertical movements, behavior, and habitat of Bigeye tuna (Thunnus obesus) in the equatorial eastern pacific ocean, ascertained from archival tag data. Marine Biology 157:2625-2642.

Stephens, D. and J. Krebs. 1987. Foraging theory. Princeton University Press, Princeton, New Jersey, USA.

Swimmer, Y., L. McNaughton, C. Moyes, and R. Brill. 2004. Metabolic biochemistry of cardiac muscle in three tuna species (bigeye, Thunnus obesus; yellowfin, T. albacares; and skipjack, Katsuwonus pelamis) with divergent ambient temperature and oxygen tolerances. Fish Physiology and Biochemistry 30:27-35.

Thums, M., M. Meekan, J. Stevens, S. Wilson, and J. Polovina. 2012. Evidence for behavioural thermoregulation by the world's largest fish. Journal of The Royal Society Interface rsif20120477.

Wang, Z., S. F. DiMarco, S. Ingle, L. Belabbassi, and L. H. Al-Kharusi. 2014. Seasonal and annual variability of vertically migrating scattering layers in the northern Arabian Sea. Deep Sea Research Part I: Oceanographic Research Papers 90:152-165.

Watanabe, Y. Y., K. J. Goldman, J. E. Caselle, D. D. Chapman, and Y. P. Papastamatiou. 2015. Comparative analyses of animal-tracking data reveal ecological significance of endothermy in fishes. Proceedings of the National Academy of Sciences USA 112:6104-6109.

Whitlock, R., A. Walli, P. Cermeño, L. Rodriguez, C. Farwell, and B. Block. 2013. Quantifying energy intake in pacific bluefin tuna (Thunnus orientalis) using the heat increment of feeding. The Journal of Experimental Biology 216:4109-4123.

Whitlock, R. E., E. L. Hazen, A. Walli, C. Farwell, S. J. Bograd, D. G. Foley, M. Castleton, and B. A. Block. 2015. Direct quantification of energy intake in an apex marine predator suggests physiology is a key driver of migrations. Science Advances 1:e1400270.

Young, J. W., B. P. Hunt, T. R. Cook, J. K. Llopiz, E. L. Hazen, H. R. Pethybridge, D. Ceccarelli, A. Lorrain, R. J. Olson, V. Allain, et al. 2015. The trophodynamics of marine top predators: current knowledge, recent advances and challenges. Deep Sea Research Part II: Topical Studies in Oceanography 113:170-187.

SUPPORTING INFORMATION

Additional supporting information may be found in the online version of this article at http://onlinelibrary.wiley.com/ doi/10.1890/15-1130.1/suppinfo 